\title{
Chapter 3. The Elder and the Younger - Foreign and Autochthonous Origin and Hierarchy in the Cook Islands
}

\author{
Jukka Siikala
}

\section{In Principle, Everything is so Simple}

For quite some time the Polynesian hierarchical systems seemed to be so simple. They were formed through chiefly lineages, in which a system of primogeniture reigned. Those, who were genealogically closest to the gods were also socially superior, and this divinely derived superiority was inherited from first born to first born (Koskinen 1960; Sahlins 1958). This normative notion of early anthropological literature has found its way to the islands through the literary interpretations of western anthropologists to such a degree that it has been constantly recollected in the field. But the origin of this kind of account cannot be found in anthropological interpretations only. In the Cook Islands one of the most important literary sources for the people of their own culture is "The Genealogy of the Kings of Rarotonga and Mangaia", published by W.W. Gill in 1890. It is a compilation which attempts to link together all the fragments of genealogical information Gill was able to collect during his long stay as a missionary in the islands. It can be regarded as one of the prototype interpretations of its kind, quickly followed by a number of genealogical accounts of the history of the archipelago.

The interest behind these accounts was historical. They represented an attempt to reconstruct the past movements of people and "tribes" from one island to another. The use of genealogies for this kind of purpose was based on the presupposition of a normative patrilineal succession. It was this succession which was the basis of the linkages between different genealogical fragments and thus in fact complete historical reconstruction. Interestingly enough, the Europeans first systematically interested in genealogies were colonial officials occupied in the first great task of their administration: the organization of land rights. The normative legitimating power of the genealogies increased with this help from outsiders, which explains the later interest of the islanders in their "complete" genealogies.

Of course in Bourdieuan outward oriented discussion emphasizing the normative aspect of culture, it is easiest to explain the intricacies of a social system in simplified, normative terms (Bourdieu 1977:18). This simplification, however, decreased the number of the legitimating and hierarchy-establishing 
qualities in a significant way. Relative age and genealogical proximity are of course, legalistic arguments, but culturally genealogies contain much more, and the legitimation of a hierarchy is dependent on a much wider scale of qualities.

Although in principle a simple distinction, the elder/younger - the basis of seniority - opposition has been the subject of refined analysis. The discussion about the relationship between the elder and the younger has culminated in the opposition between prescription and performance, "historylessness" and historical character of the society. This is especially emphasized by Valerio Valeri (1990). In his comparison of Hawaiian and Tongan societies he found in Tonga "a refusal to tolerate (or perhaps acknowledge) hierarchical ambiguities in the elder/younger relationship" (Valeri 1990). According to his interpretation this is in total contrast to the Hawaiian situation, where history enters the chiefly rivalry in a more direct way. There the younger person can take possession of a chiefly position without being transformed into a senior person, which is what happened in the mythical case of 'Aho'eitu in Tonga. After the heavenly inversion, the younger brothers of Hau do not, according to Valeri, even dream of taking the position of Tu'i Tonga. The stable Tongan normative system thus negates history, and reproduces the mythical transcendent situation again and again. To this he sees the Hawaiian system standing in complete contrast. There the younger brother can be a chief as younger and does not need to be transformed into a senior brother.

The Hawaiian chiefly system is immanent, not transcendent; unstable, not stable and, accordingly, the systems of legitimation in these societies must correspondingly stand in opposition to each other. In Tonga it is the genealogy; in Hawaii the historical performance of the king which forms the basis of the legitimation of his position. Tonga thus seems to correspond to the ideal-typical image of early anthropology.

Aletta Biersack has complicated this situation with her emphasis on the Tongan distinction between "blood" and "garland". The garland is the title, which, according to her interpretation, can be acquired as well as inherited. In the famous case of Tupou I the ability of the Tongan Hau to dream and even take the position of Tu'i Tonga was well manifested (Biersack 1990). Valeri's notion about the historyless Tongans and the historical Hawaiians is thus a normative image based on the prevailing mode of political ideology in the islands. This structural difference is of course an important one, but structures apart, both societies seem to be historical, and have been able to produce new political constellations even against the rules or ideological norms. The stereotypic reproduction is not the predominant mode of historical reproduction even in Tonga.

In all their complexity the Polynesian hierarchical systems cannot be fully comprehended by uncomplicated models. The number of possible opposing 
factors acting as hierarchy-generating operators has been and still is very large. The more complex versions of the normative system promoted and made famous by, for example, Marshall Sahlins (1981) add to the principal distinctions of human/divine, younger/elder the third pair: foreign/autochthonous. According to Sahlins, the power is from abroad; it is foreign to the people and the society, and thus transcends the limits of ordinary human beings. The foreignness of the power, however, requires the creation of a bond between the power and the people, and thus marriage and gender distinctions begin to play an important role. It is possible to go still further, and look for differences in foreign power and different kinds of relations between this foreigner and the people of the land. Highly stratified and politically relatively unified Hawaii and Tonga, with the focus of their political life in the relationship between chiefs and the people, blur the distinctions between, for example, the different islands and the systematic qualitative differences which the people themselves attribute to these. With this in mind, I will in the following look into the hierarchical relationships in the southern Cook Islands and the interplay of genealogical and other cultural operators.

\section{Ngaputoru}

\section{Origin}

The three islands of 'Atiu, Ma'uke and Mitiaro form one of the local polities which can be regarded as having had some degree of internal political coherence in the form of overarching chiefly authority at the beginning of colonial contacts (Siikala 1990). This unity of the Ngaputoru group is emphasized also in the historical narrative accounts - mythical in nature - about the origin of both the islands and their populations. These origin narratives establish a connection between divine and human worlds, but at the same time they also reveal the same transcendent reversal of the younger/elder relationship as the myth of 'Aho'eitu. The origin narratives of both 'Atiu and Ma'uke tell about the migration of the original founding chiefs from Avaiki. Typical to these heroic figures on both islands is that they were renegades, younger brothers who had to leave their original home island because of a lack of land or because of a defeat in a fight. Their travel from the transcendent Avaiki, however, transforms them into chiefs who are able to establish their own reigns on the new islands they now occupy.

In the case of 'Atiu, historically the dominant of the islands, the origin of the population is claimed to descend from Tura. The historical narrative about Tura gives a clear picture of his genealogical position:

Ina-tokoai-kura lived with her husband, who was Tangaroa. He was called Tangaroa because he was a god and he was said to be a bird. This is why our island is called Enuamanu. Some say differently, but this is 
mine. Ina-tokoai-kura lived with her husband Tangaroa, and they had their children, whose names were 'Atiu Mua, whom some people say is Mariri, the first was 'Atiu Mua, the second was 'Atiu Nui and the third was 'Atiu Iti. 'Atiu Mua had two children, Papa and Tuariki. 'Atiu Nui had a son, Mariri, this was 'Atiu Nui's second child. 'Atiu Iti, Ina-tokoai-kura's third child by Tangaroa, had Tura Ariki.

The genealogy of Tura looks as follows:

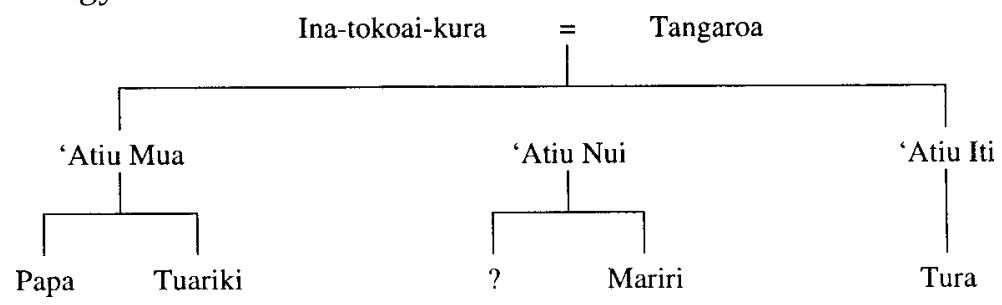

'Atiu Iti thus seems to be the youngest of the three sons of the shade of a woman, Ina-tokoai-kura and Tangaroa, who was said to be a god and a bird. And from this youngest grandchild the population descends. The other two, 'Atiu Mua and 'Atiu Nui (also known as 'Atiu Muri) gave birth to other significant descendants, among whom Tura also stands in a teina-tuakana-relationship. 'Atiu Mua is said to have given birth to Papa, who is the earth. 'Atiu Nui's descendant is in turn Mariri, to whom the bird-motif is also attached. He is known by the name Mariri-tutu-a-manu, Mariri-the-image-of-a-bird.

There seems so to be a system prevailing in this account. The human beings are the younger brothers, and the elder ones remind us more of gods; they are connected through their superior abilities, for example, to fly like Tangaroa. It is the youngest of the whole genealogical structure, Tura, who has to leave the supernatural homeland and go to look for an island for himself. The arrival of the canoe of Tura at 'Atiu from Avaiki marks the beginning of the population there.

The origin of the Ma'uke population is similarly narrated in a migration myth, according to which Avaiki was filled with blood, and the tribes there were at war with each other. The son of Tangaroa had to leave the island and travel to look for another island to live on. The origin of the Ma'uke population is thus also divine, but however from the side of the loser in war. The people originate from those who are not able to secure a place for themselves in Avaiki, which is thus left to the gods alone.

In both cases the origin is not through the paramount lines, but through the younger and losing ones. The transcendent character of the origin leaves the elder lines in Avaiki and gives them more of the attributes of the gods, while it transforms the younger ones into chiefly human beings through their travels. In this respect the Ngaputoru situation is structurally homologous to the Tongan 
'Aho'eitu case. The overall situation leads, however, to different conclusions. The third island of the group, Mitiaro, has to thank both for its soil and for its population of the other two islands. The soil was transferred by gods and spirits from 'Atiu and Ma'uke to Mitiaro to make it inhabitable, and in a similar way the descendants of 'Atiu and Ma'uke populated the island. Mitiaro thus falls totally in a youngest-descendant category in the polity of Ngaputoru. The parents of this descendant are 'Atiu and Ma'uke, which have gender values attached to them. 'Atiu is the male, and thus father; and Ma'uke is the female and mother. Hierarchically significant distinctions in this island polity are accordingly the positional distinctions between the members of a nuclear family which are used as a metaphor for the whole political system. The elder/younger opposition plays a role in the origin narratives as a marker between gods and humans, the markers of the political hierarchy are the gender values and parent/child relationships. If we look at the origin narratives from the point of view of their politically significant end-result, this is the whole significance of these. Through their mutual relationships the islands acquire their qualities, and these qualities in turn determine each island's hierarchical position.

\section{Genealogy or Genealogies: Path and Birth}

\section{Path}

The origin narratives which at the same time tell both about the migration of the original ancestors from the mythical homeland to the present day islands and give their genealogies, create the qualitatively separate island populations. The role of the resulting genealogical accounts consequently is not only to provide a genealogical link to the ancestor, or even to his divine forefathers, but to convey the qualities connected to the ancestor in question. This in turn can ensue in several ways, and accordingly there has to be several kinds of genealogies.

The genealogical representation of the present day population on the islands is a complex one. We do not have a simple distinction between historical narratives and uniform genealogical accounts, and even the genealogies are of varied kinds. My argument is that we have to make a clear distinction between genealogical information on the basis by which we as anthropologists are able to construct extremely encompassing genealogies and different genres of genealogies as they are used and recited on the islands. The politically significant ones are these genres, and not the possible sum of information in our notebooks. To draw conclusions based on comprehensive reconstructions in the way of the early anthropologists and colonial administrators is, of course, a legitimate pursuit. What is not tenable, however, is to claim that these kinds of conclusions are based on local genealogical representations of the society. For this purpose one has to look for the genealogies as they are really used. 
Visually and logically, the simplest kind of genealogy is a straight list. It begins with the name of one of the founding ancestors, lists all the intermediating ancestors, and ends with the individual whose ascent is being represented. The term used for such a genealogy is ara, the road or the path. To give an example from a Ma'ukean familybook, one ara reads:

Te ara is Koumu (The road of Koumu)

Tekeunui
Tekeumaina
Upokonui
Teenui
Tekatake
Atiuru Upoko
Utatakienua
Oe
Utaavarau
Tangaavarau
Koumu

Koumu's road to an ancestor called Tekeunui is thus represented with the help of a list of names which is claimed to be a genealogy. Te Rangi Hiroa describes this kind of genealogy in Tongareva: "a particular line of descent from a specified ancestor is called ara (a path) ... A person who is descended from more than one member of that family has more than one path (ara) to [a specified ancestor] and in a recital runs them down in order of seniority" (Buck 1932). In the Cook Islands, especially in the minute books of the land court, numerous examples are to be found in which an individual's "path" to a common ancestor is given through a number of different "paths". This is especially important in the case of candidates for a chiefly title. A combination of several paths can be claimed to provide a candidate with a stronger case, and the production of these combinations naturally requires more comprehensive genealogical knowledge, too. Rongomatane Ngakaara presented five versions of his genealogy as "different paths" in an argument over his chiefly position to the Land and Titles Court in 1903 and all of them were recorded as "genealogies of Rongomatane through different lines of ancestry".

The interesting point in these chiefly paths is the way in which they combine the ascent to different original ancestors. So we have a picture in which the three chiefs of the islands construct their paths to the two ancestors of their own island. 


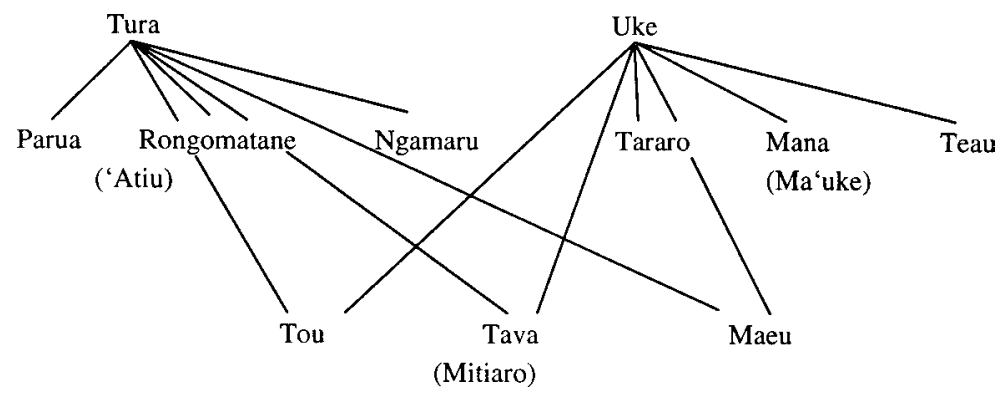

The paths give a clear image of the independent origin of 'Atiu and Ma'uke. Only Mitiaro seems to be dependent. The paths lead, however, also to the ancestors of the neighbouring islands. These paths can be used as supporting evidence for a chiefly candidate's claims. Alone, the connections to "wrong" ancestors are not sufficient; on the contrary, vague links to the ancestor of one's own island and strong links to the ancestor of the neighbouring island can be used as counter argument. In the case of 'Atiu and Ma'uke the autochthonous origin of chiefly titles is a rule. As Tura is the hierarchical descendant of the 'Atiu chiefs, so Uke is his Ma'uke counterpart and they are the end points of the paths of the genealogies of their islands.

The ara form of genealogy seems to correspond closely to the western concept of descent. The focus of the paths is not, however, unilineal descent, but ascent, and the path can, in fact, not be directly translated into inheritance rights, although this legalistic reinterpretation of paths of ascent as lines of descent is now the norm, according to which the people in the Cook Islands have adapted their own interpretation of their genealogical data. The connotations of ara have begun to deviate even from the Tikopian ones described by Raymond Firth. During the ritual of the sacred canoes in generally patrilineal Tikopia, ara is a term used to refer to the relationship between mother's father and daughter's son, between Kafika and Taumako clans (Firth 1967:135, see also Hooper 1981:19). In eastern Polynesian languages ara alludes to progeny and birth in general, without any patrilineal connotations (see Koskinen 1963:68-69).

\section{Birth}

The path is not, however, sufficient even at the level of a formalized representation to account for the continuation of life on an island. As important as the path is, birth and marriage ties begin to play havoc in the minimalism of name list genealogies (see also McKinnon 1990). The single path multiplies itself, and the possibilities of choice and the political pragmatism connected with the preferences become central. At the same time all the connotations of the path become clear, adding further arguments against the legalistic descent-line interpretation of ara. 
In addition to the simple "path" form of genealogy, there is another formalized mode of genealogical recitation and, since the coming of missionaries at the beginning of the last century, also writing. This more complex form is not a single path, but a combination of generations and marriages. It is produced patrilineally around the expressions "so and so no'o ki te vaine so and so, anau tana ..." ("so and so lived with the woman so and so and so and so was born to them") and the result is a genealogy called papa'anga. The term refers to layers or growth as does its synonym tupu'anga. The addition is a minor one, but it brings a totally new dimension to genealogy: marriage ties. In the simple path mode the sex of the generations is insignificant. In my calculations I have found that about 30 per cent of the names mentioned in the "paths" of the chiefs are female, but the sex is never mentioned. First the no'o ki te vaine ... anau tana mode of genealogical representation gives some patrilineal emphasis to the genealogies (if it is not expressed in the form no'o ki te tane, lived with a man ...).

In the political context of Ngaputoru marriage ties and thus reproductive ability play an important role. The origin narratives do give an asymmetric image of these abilities to the first generations. Uke finds a wife on his journey to the new island of Ma'uke. In a significant manner this wife is not a virgin; on the contrary, she is a wife of a warrior whom Uke kills in a fight. Uke's wife also has a son from the killed warrior, and this son becomes the husband for Uke's first born daughter. Uke thus brings to his island all the prerequisites for society: edible plants, rituals, wife, and husband for his future daughter. On 'Atiu in turn, Tura comes alone and has no wife. Accordingly, 'Atiu has to rely on Ma'uke for female reproductive powers, and Tura has to marry the second born daughter of Uke. Thus Ma'uke's position is an ambivalent one: on the one hand, the island is more complete, and thus hierarchically above 'Atiu; however, in the context of Ngaputoru politics it acquires the status of a tributary wife-giver, and thus becomes hierarchically below 'Atiu. The genealogical situation between the islands begins to look like this:

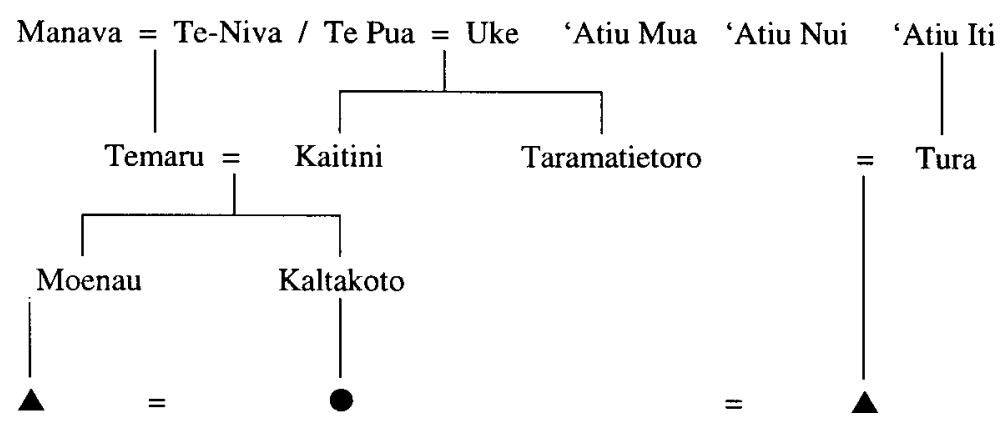

Figure. 1. Genealogical connections of Ma'uke and 'Atiu. 
According to this genealogical construction Moenau seems to be the representative of the senior line on Ma'uke. He also appears on all the genealogies of the Ma'uke chiefs in a prominent position. The two marriage ties around the daughters of the younger Ma'ukean line represent the decisive alliances, which finally determined the power on the island. The intermarriage of the chiefly lines of both islands, however, creates a situation in which all three chiefs of both islands have paths to both of the mythical ancestors, both to Uke and to Tura.

\section{Path and birth combined}

Marriage, although clear on the level of genealogical representation, is not so systematic in the Ngaputoru context after all. The genealogies give reason to wife-giver/wife-taker analysis and to the consequent emergence of hierarchical levels. In fact, marriages are not transactions connected with social prestations, gift-exchange, etc. The significant way of "living with a woman" (no'o ki te vaine) in the historical narratives is to visit a woman secretly, possibly a wife of somebody else, and have offspring. The recurring feature of the narrative accounts about the deeds of the heroic chiefs in the Cook Islands is that the chiefs have heard about a beautiful wife on another island. This competition for women is the leading force behind the raids and interisland wars. A paradigmatic example in the Ngaputoru political context - an example which still creates hectic disputes wherever Ma'ukeans and 'Atiuans meet - is the case of Akaina. He was Parua Ariki of 'Atiu, and had heard about a beautiful wife of a Ma'ukean chief. So he decided to sail over to Ma'uke to fulfil his desire. The narrative tells us how Akaina arrived on the shore and met there the husband of the woman. In typical 'Atiuan fashion, their version tells how Akaina replied to the inquiry about the purpose of his visit: "I heard about a beautiful woman named Eturere. I have come to sleep with her." To this the husband of Eturere replied: "Welcome, Akaina, we will go to the house". Without opposition he gave his wife to Akaina, who slept the night with her. The men of Ma'uke, however, were not quite satisfied with the situation, and organized a war party to kill Akaina. In this they succeeded, and the killer was the paramount Ma'uke chief Mana's warrior. Mana's younger brother in turn helped the younger brothers of Akaina to escape and return unharmed to 'Atiu. In consequence of this love affair and ensuing fight the 'Atiuans revenged, and transferred the chiefly title on Ma'uke from the tuakana to the teina, from the elder brother Mana to his younger brother Tava, the helper of Akaina's younger brothers.

In the case of Akaina the result was not birth, but death. Both can have effects on the chiefly succession and the emergence of hierarchy. It is notable that successful genealogical use of the secret deeds of a travelling chief combines path and birth, and gives path its literal meaning, i.e., the way the ancestor has been travelling. In the history of Tangiia, written down by Te Rei Tamuera and 
Stephen Savage, we have an example of the way the combination is made. In this narrative Tangiia arrives from the sea to the coast of Huahine. There he is sighted from the land, and an attempt is made to prevent his landing. According to the narrative, Tangiia composes an aka-enua song:

The land is Huahine

The ariki is Uki-manaka

Uki-manaka took Rakanui to wife ( $k a$ no'o ki te vaine ...)

And they begat Tiraonge ... (anau tana Tiraonge)

The path to Huahine is flat (paraaraa te ara ki 'Uaine)

Now let me land.

(Savage 1907:13)

Travelling Tangiia is really "on the path" of his ancestors. The aka-enua is a song composed to demonstrate his kinship ties to the island where he is trying to land. The decisive proof is one's position on the same path, the ability to trace the way the ancestors have travelled - even secretly. The path, the way the ancestor has travelled, and the descendant's attempt to trace that path are actually a Polynesian type tale. The typical tale "tells of a high chief who weds away from home and departs, leaving tokens with the mother for the child about to be born by which the child's paternity may be recognized" (Beckwith 1970:478). So the ara is not the descent, but rather the path, of the ancestor. Through their travels the warriors and chiefs create not only genealogical links between different islands, but at the same time a differentiated political space, which is hierarchically organized; and this hierarchy is expressed in genealogical terms. In a dispute about the seniority of rival islands claiming genealogical connections to the same heroic ancestor, the order of his visit to the islands is decisive. The ara of the islands is dependent on the route or path of the hero.

The narrative about Akaina is a paradigmatic one because it reveals the constantly recurring pattern, according to which the marriage ties between Ma'uke and 'Atiu affect the chiefly succession. It is not only the hierarchical relationship, but also the gendered values of the different islands which are the determinants of the political power. 'Atiuans as males and lonely warriors of the original genealogical situation reproduce their position by constantly travelling to Ma'uke "to prey for food and women" as Ron Crocombe put it (1967). At the same time the Ma'ukeans proliferate their position as senior and female.

The marriage alliance in this situation is a strange one: it is an alliance without marriage. There is the travelling male and the beautiful woman of the land whom the male visits. He does not stay, but continues his travel, and the paths of these travellers form a web of relationships around the archipelago. The hierarchical 
position of the island societies in the total polity is determined by the combination of the paths and the births, travels and sexual values of the islands.

\section{Mana enua, mana tangata}

In the social situation of the origin genealogies of Ngaputoru, only Ma'uke is complete and able to reproduce itself. 'Atiu, in contrast, is given as a lonely warrior who has to conquer a wife for himself on some other island. This leads to the original marriage between Ma'uke and 'Atiu, and the conceptualization of the island communities continues to give them the values of a husband and a wife, a man and a woman. 'Atiu is claimed to be the island of warriors and Ma'uke the island of va'ine purotu, the island of beautiful women, whose beauty is praised in numerous songs.

The conquering of the Ma'ukean women by 'Atiu warriors has not, however, occurred against the will of the Ma'ukeans. In the internal classification of younger and elder lines the connections to the warriorlike 'Atiuans play a decisive role. The internal chiefly rivalry constantly seeks a means of legitimation outside its borders. The interplay of the values of female and wife-giver, male and wife-taker result in the intervening fame of the women's beauty or the event of outside wife-conquering. The alliances created on this basis are unstable ones, and can be understood only as valued by the precedence of a whole set of categorical operators (Fox 1994). When wife-giver is defined as female, it is seen as inferior to the conquering male wife-taker. When the chiefly family is not seen as wife-giver but a senior beautiful woman whose beauty the travelling chiefs can not resist, the external wife-conqueror is utilized to support the claims of the internal chiefly line in question. The set of operators thus includes the distinctions between elder/younger, female beauty/male conqueror, autochthonous/foreign. The complementary combination and consequent reversals of the values of social units on the basis of the application of these categories forms the dynamics of chiefly politics.

In the case of Akaina, the killing of the love-hungry visitor led to the transfer of the title from one line to another. Similarly, the giving of daughters as wives to 'Atiu chiefs gives the candidates for a title a decisive advantage: the support of the island of warriors.

The continuation of this situation has not led to a complete and genealogically legitimated 'Atiu dominance in the archipelago, despite the early European impressions and some later interpretations. The path of the Ma'uke chiefs guarantees them their seniority because they can trace their path through the seniors, and the path of the 'Atiuans always passes through the juniors. But this is so only if the path is traced to Uke, the original ancestor of Ma'uke. The place and the ancestor are tightly connected, and the path metaphor highlights this connection. The path is not only the way of counting genealogies, it is also the 
path of the ancestor and his qualities from beyond to the present island. This ties together the place and the genealogy in a mutual legitimation. A genealogy can be used in one place, but not in another because both are actually expressions of the same process, the extension of the ancestral tumu in space and time. Correspondingly the seniority of one place can turn out to be juniority in the context of the polity of the whole archipelago. Precedence is determined in a recursive way, creating an overall social hierarchy.

The place-bound character of precedence is manifest also in the duality of power. Mana enua, power over land, can only be possessed by somebody who has a legitimate path to the original ancestor of the place. Conquest did not lead to the alienation of land in the Ngaputoru group. Even if it did, the conqueror had to create genealogical and even legitimate (i.e., through senior lines) connections to the ancestor of the place. Mana tangata, power over people, in turn, is able to emerge on the basis of marriage alliances abroad, and is thus able to transcend the horizon of a single island. The duality of power gives rise to a political situation of a relatively stable system of precedence in which a total reorganizing of the power structure in the Hawaiian style is impossible (cf. Valeri 1990).

The 'Atiu chiefs, who held absolute political power in the Ngaputoru group, were tuakana, or elder brothers, but they only possessed mana tangata, power over people. This power did not enable them to deprive the people of other islands of their land. The Ma'ukeans had mana enua on the basis of their path to the ancestor of their own land, and this path reversed the precedence in relation to the place. The overall authorities were said to be juniors, if they came to Ma'uke, because the point of reference - the operator - changed.

\section{References}

Beckwith, Martha

1970 Hawaiian mythology. Honolulu: University of Hawaii Press.

Biersack, Aletta

1990 Under the Toa tree. The genealogy of the Tongan chiefs. In Jukka Siikala (ed.) Culture and history in the Pacific, Vol. 27, 80-106. Helsinki: Transactions of the Finnish Anthropological Society.

Bourdieu, Pierre

1977 Outline of a theory of practice. Cambridge Studies in Social Anthropology. Cambridge: Cambridge University Press.

Buck, Peter H. (Te Rangi Hiroa)

1932 Ethnology of Tongareva. Honolulu: Bernice Pauahi Bishop Museum Bulletin 92. 
The Elder and the Younger - Foreign and Autochthonous Origin and Hierarchy in the Cook Islands

Crocombe, Ron

1967 From ascendancy to dependency: the politics of 'Atiu. The Journal of Pacific History 2:97-111.

Firth, Raymond

1967 The work of gods in Tikopia. London School of Economics Monographs on Social Anthropology Nos 1 and 2. London: The Athlone Press.

Fox, James J.

1994 Reflections on "hierarchy" and "precedence". In M. Jolly and M. Mosko (eds) Transformations of hierarchy: structure, history and horizon in the Austronesian world. History and Anthropology, Vol. 7, 87-108. Chur and Reading: Harwood Academic Publishers.

Gill, William Wyatt

1890 The genealogy of the kings of Rarotonga and Mangaia, as illustrating the colonisation of that island and the Hervey Group. Australasian Association for the Advancement of Science 2:627-637.

Goldman, Irving

1970 Ancient Polynesian society. Chicago: University of Chicago Press.

Hooper, Antony

1981 Why Tikopia has four clans. Occasional Paper No. 38. London: Royal Anthropological Institute of Great Britain and Ireland.

Koskinen, Aarne A.

1960 Ariki the first born: an analysis of a Polynesian chieftain title. Helsinki: Suomalainen Tiedeakatemia.

1963 Linking of symbols: Polynesian patterns 1. Helsinki: The Finnish Society for Missionary Research.

McKinnon, Susan

1990 The matrilateral transference of power in Tikopia. The Journal of the Polynesian Society 99(3):227-264.

Sahlins, Marshall

1958 Social stratification in Polynesia. Monographs of the American Ethnological Society. Seattle: University of Washington Press.

1981 The stranger-king; or, Dumézil among the Fijians. Journal of Pacific History 16:107-132.

Savage, Stephen and Tamuera Te-Rei 
1907 An ancient history of Tangiia. MS, The Australian National University Library, Canberra.

Siikala, Jukka

1990 Chiefs, gender and hierarchy in Ngaputoru. In Jukka Siikala (ed.) Culture and history in the Pacific, Vol. 27, 107-124. Helsinki: Transactions of the Finnish Anthropological Society.

Sissons, Jeffrey

1989 The seasonality of power: the Rarotongan legend of Tangiia. The Journal of the Polynesian Society 98(3):331-347.

Valeri, Valerio

1990 Diarchy and history in Hawaii and Tonga. In Jukka Siikala (ed.) Culture and history in the Pacific, Vol. 27, 45-79. Helsinki: Transactions of the Finnish Anthropological Society. 